\title{
Mark Smith: Pioneer of Alzheimer Disease Research
}

\author{
Hyoung-gon Lee $\cdot$ George Perry $\cdot$ Xiongwei Zhu
}

Received: 18 July 2012/ Accepted: 18 July 2012/Published online: 27 July 2012

(C) Springer Science+Business Media, LLC 2012

This issue of Neurotoxicity Research honors Mark A. Smith. While we will never know the plan that suddenly took him from us almost 2 years ago, his pioneering work and original ideas will live on and influence contemporary thought in Alzheimer disease (AD) research. Mark defined the first oxidative modifications found in AD and pioneered the foundation for cell cycle alteration and metabolic changes. He was also known for questioning the amyloid cascade hypothesis, providing evidence that amyloid- $\beta$ $(\mathrm{A} \beta)$ and tau are protective responses to brain injury. Consequently, his efforts were concentrated on connecting AD to biology, leading to the two-hit hypothesis and other theories which focused on the pleiotropic threshold between pathology and physiology. In his early work, Mark demonstrated oxidative modification of every category of biological macromolecule: protein, carbohydrate, lipids, and nucleic acids. But it was Mark's rapid comprehension that oxidative damage is countered by an antioxidant response that bound his ideas. Coincident with pathology he reported protective physiological responses and cell cycle re-entry. These findings defined a new concept in oxidative stress, one of homeostasis where radicals do not breach defenses, but a new balance is reached, designed to protect cells from death. Mark's work on neuronal death changed the view of neuronal apoptosis; rather than dying, neurons in $\mathrm{AD}$ resist death through induction of many of the pathways linked to apoptosis, but without completion of the death response these changes played a role in neuronal survival.

In this special issue, we have been fortunate to gather foremost experts in the field to discuss the current state of these exciting areas. We thank the contributors that remind us of Mark's great vision and contributions to understanding the pathogenesis of AD. We also owe a great debt of gratitude to Dr. Richard Kostrzewa for the opportunity to compile this issue. Lastly, we hope that the contributions from Mark's legacy will continue to contribute to further research on finding the cure for AD.

H. Lee $(\bowtie) \cdot X$. Zhu

Department of Pathology, Case Western Reserve University,

Cleveland, $\mathrm{OH}$, USA

e-mail: hx154@case.edu

G. Perry

UTSA Neurosciences Institute, University of Texas at San

Antonio, San Antonio, TX, USA

G. Perry

Department of Biology, University of Texas at San Antonio,

San Antonio, TX, USA 